\title{
Patients Homozygous for the T435N Mutation of Succinyl-CoA:3-Ketoacid CoA Transferase (SCOT) Do Not Show Permanent Ketosis
}

\author{
TOSHIYUKI FUKAO, HARUO SHINTAKU, RYOU KUSUBAE, GAI X. ZHANG, \\ KOZUE NAKAMURA, MASASHI KONDO, AND NAOMI KONDO
}

Department of Pediatrics [T.F., G.X.Z., K.N., M.K., N.K.], Graduate School of Medicine, Gifu University, Gifu
501-1194, Japan, Department of Pediatrics [H.S.], Osaka Municipal University, Osaka 545-8585, Japan,
Department of Pediatrics [R.K.], Kagoshima Prefectural Oshima Hospital, Naze, Kagoshima 894-0015, Japan

\section{ABSTRACT}

Succinyl-CoA:3-ketoacid CoA transferase (SCOT; locus symbol OXCT; E.C. 2.8.3.5) is the main determinant of the ketolytic capacity of tissues. Hereditary SCOT deficiency causes episodic ketoacidosis. Permanent ketosis has been regarded as a pathognomonic feature of SCOT deficiency. There are three SCOT-deficient patients from a small region in Japan and they have not manifested permanent ketosis, even though their ketoacidotic crises were as severe as those of other SCOT-deficient patients. All three were homozygous for the T435N mutation. Transient expression analysis of wild-type and mutant cDNA showed that the $\mathrm{T} 435 \mathrm{~N}$ mutant retained significant residual SCOT activities ( $20 \%$ for that of the wild-type at $39.5^{\circ} \mathrm{C}, 25 \%$ at $37^{\circ} \mathrm{C}$, and $50 \%$ at $30^{\circ} \mathrm{C}$ ). The difference of residual SCOT activities at these temperatures in expression analyses was due to differences in the level of the mutant protein. SCOT activity of the $\mathrm{T} 435 \mathrm{~N}$ protein was more vulnerable than the wild-type to heat treatment at $42^{\circ} \mathrm{C}$ and $55^{\circ} \mathrm{C}$. These temperature-sensitive characteristics of the mutant protein may explain, in part, why the patients developed ketoacidotic crises during febrile illness. In SCOT-deficient patients retaining some residual activity, permanent ketosis may be absent. (Pediatr Res 56: 858-863, 2004)
Abbreviations
CT, cytosolic acetoacetyl-CoA thiolase
SCOT, succinyl-CoA:3-ketoacid CoA transferase
TKB, total ketone bodies

Ketone bodies, produced mainly in the liver, are an important source of energy for extrahepatic tissues (1). SCOT (EC 2.8.3.5), a mitochondrial homodimer essential for ketone body utilization, catalyzes the activation of acetoacetate to acetoacetyl-CoA. Autosomal recessive deficiency of SCOT (OMIM 245050) causes episodic ketoacidosis and is part of the differential diagnosis of childhood ketoacidosis, a frequent condition. In contrast with most organic acidemias, no diagnostic metabolites are observed in blood and urine samples from SCOT-deficient patients although the ketone bodies acetoacetate and 3-hydroxybutyrate are elevated. Since the first description of SCOT deficiency (2), only 11 affected probands have been reported (3-13). Because of the nonspecific metabolite profile of SCOT-deficient patients, in vitro methods of diagnosis are particularly important. Enzyme assays of SCOT activity are sufficient for clinical diagnosis but current whole-

Received November 6, 2003; accepted May 19, 2004.

Correspondence: Toshiyuki Fukao, M.D., Ph.D., Department of Pediatrics, Graduate School of Medicine, Gifu University, 1-1 Yanagido, Gifu, Gifu 501-1194, Japan; e-mail: toshi-gif@umin.ac.jp

Supported, in part, by a Grant-in-Aid for Scientific Research from the Ministry of Education, Science, Technology, Sports and Culture of Japan.

DOI: 10.1203/01.PDR.0000145297.90577.67 cell assays can yield a spuriously high apparent residual activity (14-16). To assist clinical diagnosis, we cloned a human SCOT cDNA (14) and SCOT gene (12), developed an anti[human SCOT] antibody (15), and have described six mutations in SCOT-deficient patients $(12,14,16)$.

A clinical clue for suspecting SCOT deficiency is permanent (or persistent) ketosis, which is believed to be pathognomonic for this condition. Most SCOT-deficient patients have permanent ketosis (1). We herein describe three SCOT-deficient patients who have not had permanent ketosis even though their ketoacidotic crises were as severe as those observed in typical SCOT-deficient patients. We hypothesized that these patients had "mild" mutations with residual SCOT activity that can prevent the development of permanent ketosis. We performed molecular analyses to test this hypothesis.

\section{MATERIALS AND METHODS}

Patients and cell lines. Informed consent for enzymatic diagnosis and molecular analyses was obtained from GS08's mother and GS09's parents. Informed consent was obtained for a fasting test from GS08's mother, and for ketone body evaluation during 2 d from GS09's parents. This study was ap- 
proved by the Ethical Committee of Gifu University School of Medicine.

Fibroblasts from GS08 and her mother were cultured in Eagle's minimal essential medium containing 10\% FCS. DNA was also prepared from heparinized blood samples of GS09's family.

Enzyme assay and immunoblot analysis. Assays for acetoacetyl-CoA thiolase and for SCOT were as described previously $(7,17,18)$, using acetoacetyl-CoA as a substrate and measuring its disappearance spectrophotometrically. Immunoblot analysis was as described previously (15), using a mixture of anti-[human SCOT] antibody and anti-[rat mitochondrial acetoacetyl-CoA thiolase] antibody as the first antibodies and $30 \mu \mathrm{g}$ of fibroblast protein extract.

Mutation analysis. Mutations were detected by amplifying from patient fibroblasts a cDNA, spanning the full-length coding sequence, and sequencing six clones. Total fibroblast RNA was purified with an ISOGEN kit (Nippon Gene, Tokyo, Japan). RT-PCR was as described (16).

Genomic DNA was purified with a Sepa Gene kit (Sanko Junyaku, Tokyo, Japan). A genomic fragment, including exon 14, was amplified with a sense primer (5'-CTGTCACATACAAAAGAAGTG-3') and an antisense primer (5'CCAAAAGCAGT-ATTTGGGGAGCACA-3'). The PCR conditions were 40 cycles at $94^{\circ} \mathrm{C}$ for $1 \mathrm{~min}, 54^{\circ} \mathrm{C}$ for $1 \mathrm{~min}$, and $72^{\circ} \mathrm{C}$ for $2 \mathrm{~min}$. The amplified fragment was subjected to direct sequencing.

To confirm the $\mathrm{T} 435 \mathrm{~N}$ mutation in familial analysis, we devised a restriction enzyme-based assay for genomic amplicons. A second PCR was done with an aliquot of the amplified exon 14 fragment described above, using a sense primer (5'GAAGATGGTGAAAGGAATGGGAGGTGCTAT-3') and an antisense mismatch primer (5'-TGCTCCATGGTGACCACCACCTTG-3'). The underlined $\mathrm{C}$ was a mismatch to introduce a StyI site in the normal but not the mutant allele. After the StyI digestion, the normal allele yields 8-bp, 15-bp, and 55-bp fragments; the mutant allele, 8-bp and 70-bp fragments. Restriction digests were resolved on a $15 \%$ polyacrylamide gel.

Construction of eukaryotic transient expression vectors. Wild-type full-length SCOT cDNA (14) were subcloned into the pTZ18U and pCAGGS eukaryote expression vectors (19) and designated the pTscotWild-type and pCAGGSscotWildtype, respectively. T435N was introduced into the pTscotWildtype using a QuikChange Site-Directed Mutagenesis Kit (Stratagene, La Jolla, CA), confirmed by sequencing, and then transferred into pCAGGS.

Transient expression analysis. Wild-type and mutant SCOT expression vectors $(4 \mu \mathrm{g})$ were transfected using Lipofectamine 2000 (Invitrogen, Carlsbad, CA) in $\sim 10^{5}$ SV40transformed SCOT-deficient fibroblasts from patient GS02, which contain no endogenous SCOT activity (18). One microgram of the cytosolic acetoacetyl-CoA thiolase (CT)expressing vector, pCAGGSct (20), was co-transfected to monitor transfection efficiency. After a 72-h incubation at $30^{\circ} \mathrm{C}$, $37^{\circ} \mathrm{C}$, or $39.5^{\circ} \mathrm{C}$, cells were harvested and stored at $-80^{\circ} \mathrm{C}$ until the assay for SCOT (18) and CT (17) activities. Immunoblot was done using a mixture of anti-[human SCOT] antibody and anti-[human CT] antibody as the first antibody. The quantity of mutant protein was estimated densitometrically by comparing it to the signal intensities of serially diluted samples of the wild-type SCOT protein.

Heat stability test for enzyme activity. A heat stability test for enzyme activity was performed using a $30^{\circ} \mathrm{C}$ expression sample of the wild and T435N mutant. The protein concentration of the supernatant was adjusted to $0.5 \mathrm{mg} / \mathrm{mL}$ with an extraction buffer, and then incubated for up to $10 \mathrm{~min}$ at $42^{\circ} \mathrm{C}$ or $55^{\circ} \mathrm{C}$. The supernatant was kept on ice for at least $5 \mathrm{~min}$ and assayed for SCOT activity at $30^{\circ} \mathrm{C}$.

\section{RESULTS}

Clinical description of GS08. GS08 is a Japanese boy born to nonconsanguineous parents who were both from a small island (Amami Island). He was well until 17 mo of age, when he developed vomiting and unconsciousness and was admitted to a hospital. Laboratory testing showed pH6.96, base excess $-30.7 \mathrm{mEq} / \mathrm{L}$. After i.v. fluid replacement and sodium bicarbonate administration $(70 \mathrm{mEq})$ to correct $\mathrm{pH}$, his blood gas still showed $\mathrm{pH} 7.01, \mathrm{BE}-28.8 \mathrm{mM}$. On the third hospital day, he regained consciousness. Serum amino acid, blood acylcarnitine, and urinary organic acid analysis were done to rule out metabolic disorders. The only positive finding was massive urinary excretion of acetoacetate and 3-hydroxybutyrate. Three months later, he again became unconscious after an upper respiratory infection with a high fever. This time, he was admitted to Osaka Municipal University Hospital. Blood pH was 7.12 , base excess $-23.5 \mathrm{mM}$, blood glucose $6 \mathrm{mM}$, blood acetoacetate $1.85 \mathrm{mM}$, 3-hydroxybutyrate, $5.78 \mathrm{mM}$. Blood lactate, pyruvate, and ammonia levels were within normal ranges. He recovered with i.v. fluid, including sodium bicarbonate. After his recovery from these ketoacidotic crises, the blood level of TKB was occasionally $<0.2 \mathrm{mM}$, indicating that his ketosis was not permanent. Urinary ketone body determination was usually negative. He experienced another ketoacidotic episode 3 mo after the second admission. He was suspected to be SCOT deficient because of multiple ketoacidotic episodes and the absence of urinary organic acids suggestive of other inborn errors. The diagnosis was confirmed by enzyme assay. At 24 mo of age, he was admitted to Osaka Municipal University Hospital again to evaluate his metabolic condition.

Fasting test. A fasting test (Fig. 1) was carefully performed to evaluate his ketotic state, for which informed consent was obtained from his parents. As shown in Figure 1, blood TKB levels were elevated to about $6 \mathrm{mM}$ at $14 \mathrm{~h}$ of fasting, and to $>10 \mathrm{mM}$ at $17 \mathrm{~h}$. The ratio of FFA to TKB decreased promptly to $<0.3$ after $14 \mathrm{~h}$. At $17 \mathrm{~h}, 2 \mathrm{mEq} / \mathrm{kg}$ sodium bicarbonate and $5 \mathrm{mEq} / \mathrm{kg}$ glucose were injected intravenously because blood $\mathrm{pH}$ had decreased to 7.29 with $\mathrm{BE}-14.2$. This injection resulted in a rapid decrease of blood TKB and FFA levels, together with blood $\mathrm{pH} 7.38$ and $\mathrm{BE}-8.1$ at $2 \mathrm{~h}$ after the injection.

The mother was instructed to prevent him from fasting longer than $12 \mathrm{~h}$ and to check for urinary ketones at home. If the urinary ketones were strongly positive, oral carbohydrate intake was to be increased. He has not experienced any further 


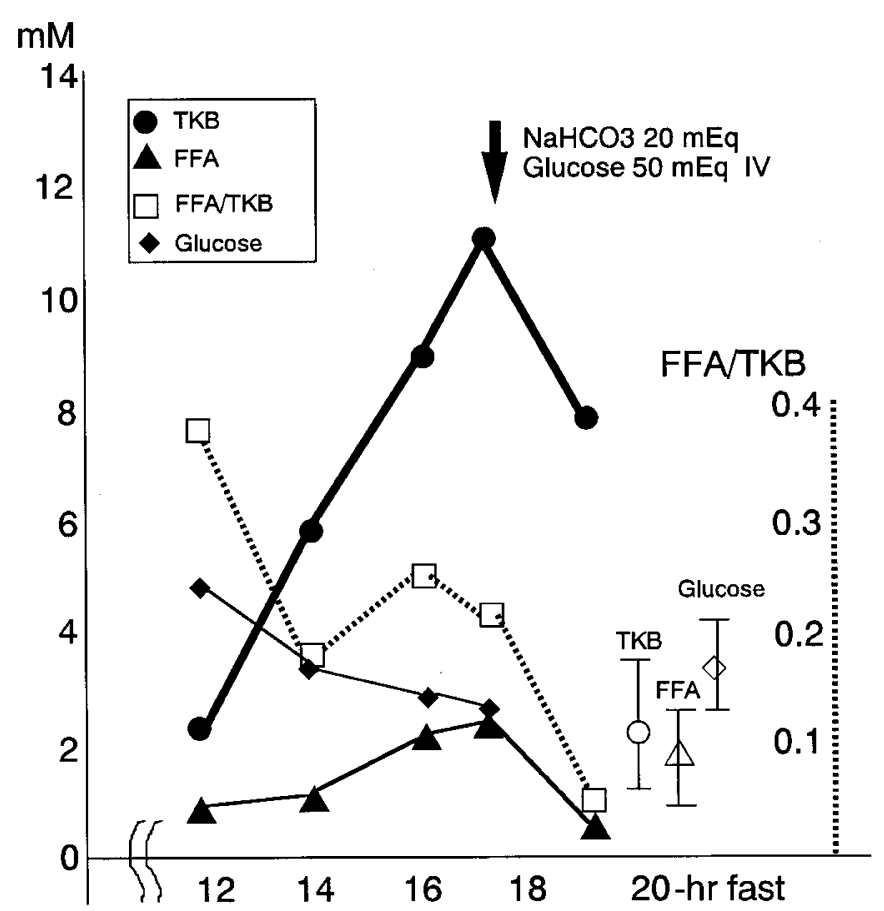

Figure 1. Fasting test of GS08. The vertical bar with open circle, that with open triangle, that with open rhombus indicate $10^{\text {th }}-90^{\text {th }}$ percentiles with mean blood levels of TKB and FFA, and glucose, respectively, in controls (1-7 $\mathrm{y}$ of age fasted for $20 \mathrm{~h}$ ) from the literature (21).

severe ketoacidotic crises. He is now 6 y of age and his development is within a normal range.

Clinical description of GSO9 and his elder brother $(\boldsymbol{G S O 9 b ) . ~ G S 0 9}$ is a Japanese boy, also born to nonconsanguineous parents from Amami Island. He developed his first ketoacidotic episode at 10 mo of age. After a 1-d episode of high fever and vomiting, he was admitted to Oshima Hospital. Urinary ketone levels were $3+$. Continuous i.v. fluid therapy was initiated but he became unconscious and polypneic. Blood $\mathrm{pH}$ was $7.09, \mathrm{BE}-23.4 \mathrm{mM}, \mathrm{HCO}_{3}{ }^{-} 5.4$ $\mathrm{mM}$. After correction of blood $\mathrm{pH}$ with sodium bicarbonate $\left(\mathrm{pH} 7.39, \mathrm{BE}-16.6 \mathrm{mM}, \mathrm{HCO}_{3}{ }^{-} 7.4 \mathrm{mM}\right)$, he regained consciousness but urinary ketones were still $3+$. After $4 \mathrm{~d}$ of i.v. fluid therapy, the urinary ketones became negative. Urinary organic acid analysis on the third hospital day showed massive ketosis with nonspecific dicarboxylic aciduria. After discharge he was examined when well. His blood TKB were $0.29 \mathrm{mM}$ and urinary ketones were negative. Two months after the first episode, he experienced a second ketoacidotic episode in association with an upper respiratory infection and a high fever. Blood $\mathrm{pH}$ was 7.14, $\mathrm{BE}-22.4 \mathrm{mM}$, and $\mathrm{HCO}_{3}{ }^{-} 5.6 \mathrm{mM}$. He recovered with i.v. fluid therapy. He was suspected of having a ketolytic defect despite his lack of permanent ketosis.

His elder brother (GSO9b) had also been admitted to the hospital four times (at $10 \mathrm{mo}, 1 \mathrm{y}, 2 \mathrm{y}$, and $5 \mathrm{y}$ of age) because of ketoacidosis. The most severe of these was at $1 \mathrm{y}$ of age. Blood $\mathrm{pH}$ was $7.00, \mathrm{BE}-25.2 \mathrm{mM}, \mathrm{HCO}_{3}{ }^{-} 5.8 \mathrm{mM}$. He was successfully treated with i.v. fluid therapy and the urinary ketones became negative. The other siblings, another elder brother of $9 \mathrm{y}$ of age and a younger sister of $2 \mathrm{y}$ of age, have had no ketoacidotic episode thus far.
The mother increased GS09's oral carbohydrate intake or took him to the hospital for i.v. fluid therapy to prevent ketoacidotic crises when he became febrile. GS09 has experienced no further ketoacidotic crises. GS09 and GS09b are currently 4 and $8 \mathrm{y}$ of age, within normal development.

Blood levels of ketone bodies at 15-h fast and postprandial conditions in GS09, GS09b, and typical SCOT-deficient patients (GSO2 and GSO2s). In the cases of GS09 and GS09b (Fig. 2), this test was performed for two successive days. In all cases at 2-h after a meal, blood TKB levels decreased to various extents (Fig. 2A) and FFA levels decreased to less than $0.25 \mathrm{mM}$ (Fig. 2B). The latter indicated that meals were sufficient to suppress lipolysis. Because the blood level of ketone bodies varies according to age, we compared the results of GS09b (8 y of age) with those of GS02 (9 y of age) and GS02s ( 7 y of age), who have permanent ketosis $(7,8,16)$. The normal range of TKB at their ages was reported to be $<0.1-0.5$ $\mathrm{mM}$ (mean, 0.2) at 15 -h fasts (21). As shown in Figure $2 A$, the blood TKB level at $15 \mathrm{~h}$ of fasting was much lower in GS09b than in GS02 or GS02s. Two hours after a meal, the TKB level remained higher than $2 \mathrm{mM}$ in GS02 and GS02s but decreased to around $0.2 \mathrm{mM}$ in the case of GS09b. In the case of GS09 (4 $\mathrm{y}$ of age), TKB levels at $15 \mathrm{~h}$ of fasting were within or slightly above the normal range (1-6 y of age), however, $2 \mathrm{~h}$ after a meal, TKB levels were higher than the normal range $(<0.1 \mathrm{mM})$. In both GS09 and GS09b, blood TKB levels were higher on the second day than the first day.

SCOT activity and immunoblot analysis in GSO8's fibroblasts. SCOT activity was assayed three times and revealed to be $\sim 37 \%$ of control values in GS08's fibroblasts $(3.4 \pm 0.1$ $\mathrm{nmol} / \mathrm{min} / \mathrm{mg}$ protein; his mother's $7.3 \pm 1.0 \mathrm{nmol} / \mathrm{min} / \mathrm{mg}$ protein; controls $(n=4) 9.0 \pm 2.1 \mathrm{nmol} / \mathrm{min} / \mathrm{mg}$ protein). On immunoblot analysis, a SCOT band was present at $25 \%$ and

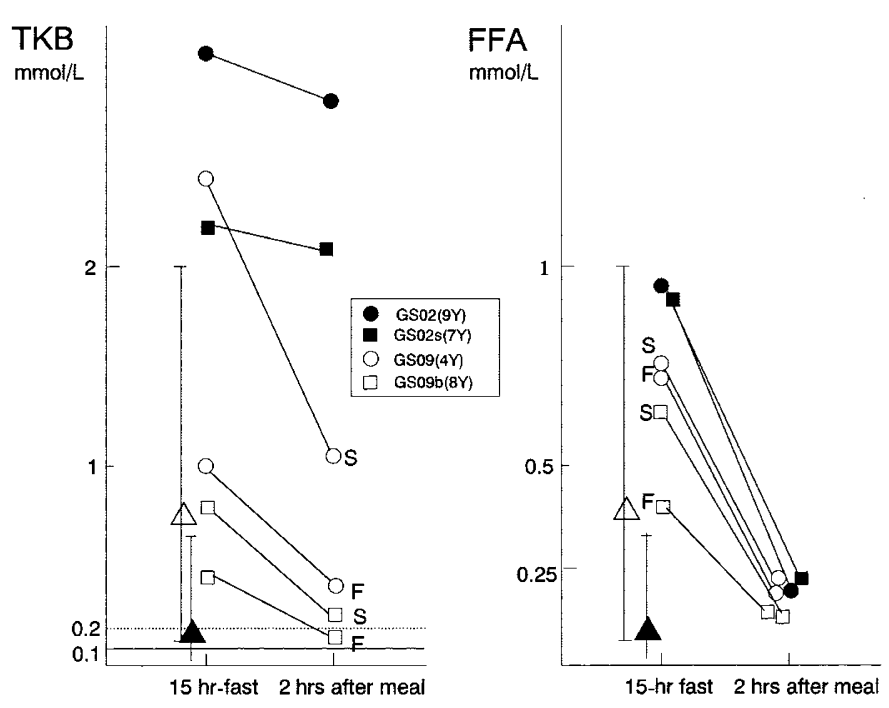

Figure 2. Blood levels of TKB $(A)$ and FFA $(B)$ at $15 \mathrm{~h}$ of overnight fasting and $2 \mathrm{~h}$ after meals in the cases of GS09, GS09b, GS02, and GS02s. In the cases of GS08 and GS08b, data for two successive days are shown. F and S indicate data on the first day and second day, respectively. The vertical bar with open triangle and that with closed triangle indicate the normal range $\left(10^{\text {th }}\right.$ $-90^{\text {th }}$ percentiles) and mean of blood levels for each compound in controls (1-6 y of age and 7-15 y of age, respectively) from the literature (21) 
$70 \%$ of control levels in GS08's and his mother's fibroblasts, respectively (data not shown). Mitochondrial acetoacetyl-CoA thiolase protein was present at similar levels in all cells studied.

Mutation analysis. Full-length cDNA was screened for GS08 and c.1304 C>A (T435N) was found in GS08 homogeneously at the cDNA level. Because GS09's parents were from Amami Island as were GS08's parents, we sequenced PCRamplified genomic fragments including exon 14 in GS09 and GS09b and identified the T435N mutation. Figure 3 shows the presence of T435N in genomic DNA fragments, distinguished from normal by specific restriction enzyme digestion patterns, in GS08's and GS09's families. GS08, GS09 and GS09b were T435N homozygotes. GS08's mother and GS09's parents were heterozygous carriers of this mutation. Another elder brother of GS09 was a T435N heterozygote but GS09's younger sister was normal. GS08's father's DNA was not available.

Transient expression of SCOT cDNA. We expressed wildtype and mutant SCOT cDNAs in SCOT-deficient SV40transformed fibroblasts (Fig. 4A). Transfection with pCAGGSscotWild-type gave significant SCOT activity compared with transfection with plasmids containing no SCOT cDNA (mock). For pCAGGSscotT435N, SCOT activity was about $20 \%, 25 \%$, and $50 \%$ that of the wild-type when cultured at $39.5^{\circ} \mathrm{C}, 37^{\circ} \mathrm{C}$, and $30^{\circ} \mathrm{C}$, respectively, indicating that the $\mathrm{T} 435 \mathrm{~N}$ mutant retains significant SCOT activity. We also examined mutant cDNAs with V133E or C456F, the mutant
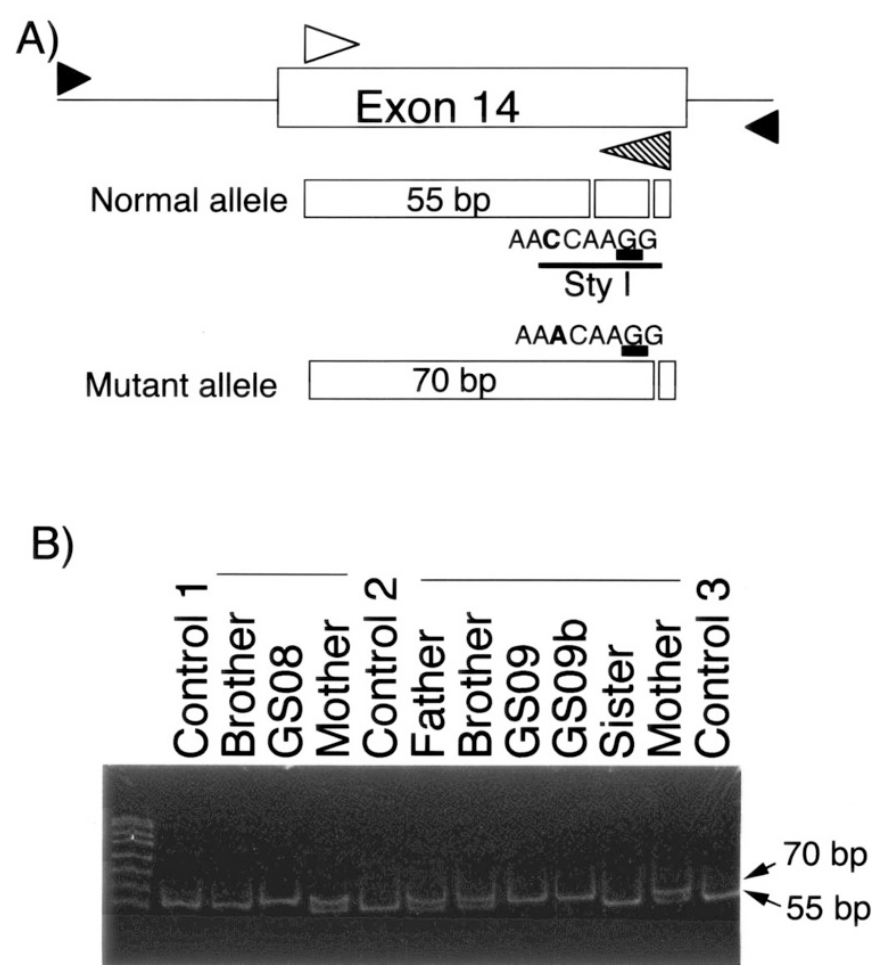

Figure 3. T435N detection schemes (upper panel) and results (lower panel) for genomic amplicons from patients, parents, and controls. Upper panel, the names and positions of primers (arrowheads) of restriction sites and the length of cleavage fragments are shown for normal and mutant fragments. Dashed arrowheads indicate primers containing a mutation to create a restriction site. Introduced residues are underlined. Lower panel, ethidium bromide-stained polyacrylamide gels of amplicons. alleles from the GS02 family. No residual activity was found with either of these mutants (data not shown).

Figure $4 B$ shows the results of immunoblot analysis of transfected cells. Transfection of pCAGGSscotWild-type gave an intense SCOT signal. The T435N mutant SCOT protein was detectable with signal intensities estimated at about $35 \%, 50 \%$, and $100 \%$ of those of pCAGGSscotWild-type at $39.5^{\circ} \mathrm{C}, 37^{\circ} \mathrm{C}$, and $30^{\circ} \mathrm{C}$ transfection, respectively. Combining the assay and immunoblot data, we concluded 1) that the specific activity of $\mathrm{T} 435 \mathrm{~N}$ is about half that of wild-type SCOT and 2) that transfection at lower temperatures gave a higher level of T435N SCOT protein relative to the wild-type.

We performed a heat stability test for SCOT activity. The activity of the wild-type SCOT was revealed to be relatively resistant to heat treatment. As shown in Figure $4 C$, incubation at $42^{\circ} \mathrm{C}$ for $10 \mathrm{~min}$ did not affect enzyme activity but incubation at $55^{\circ} \mathrm{C}$ for 10 min reduced enzyme activity to $20 \%$. In the case of the $\mathrm{T} 435 \mathrm{~N}$ mutant, incubation at $42^{\circ} \mathrm{C}$ for $10 \mathrm{~min}$ reduced enzyme activity to $50 \%$, and incubation at $55^{\circ} \mathrm{C}$ resulted in more rapid inactivation of enzyme activity $(<10 \%$ in a 4-min incubation) than the wild-type.

\section{DISCUSSION}

The three patients (GS08, GS09, and GS09b) described lack permanent ketosis but developed multiple ketoacidotic crises like other previously reported SCOT-deficient patients. Permanent ketosis is believed to be pathognomonic of SCOT deficiency. In fact, most patients described previously showed permanent ketosis (1). We recently showed that blood TKB levels were $>0.2 \mathrm{mM}$ even under continuous glucose infusion in another SCOT-deficient patient, GS07, whose mutation was devoid of any residual activity $(12,13)$. It is of importance that the absence of permanent ketosis cannot exclude the diagnosis of SCOT deficiency.

We hypothesized that GS08, GS09, and GS09b were SCOTdeficient patients with "mild" mutations that retained some residual SCOT activity and that such activity prevented these patients from permanent ketosis. This cannot be assessed in whole fibroblast assays, which show an apparent residual SCOT activity of $20-35 \%$ even in SCOT-deficient patients with null mutations in both alleles (14-16). Hence we used molecular analysis to address the hypothesis. We showed that all patients in the current report are homozygotes of T435N, which retains significant residual SCOT activity $\left(25 \%\right.$ at $\left.37^{\circ} \mathrm{C}\right)$ in transient expression analysis. In contrast, the Japanese SCOT-deficient siblings with permanent ketosis, GS02 and GS02s, are compound heterozygotes of V133E and C456F, mutations with no residual SCOT activity in transfection analysis at $37^{\circ} \mathrm{C}(16)$ or $30^{\circ} \mathrm{C}$ (data not shown).

Our results suggested that GS08, GS09, and GS09b have a $25 \%$ residual SCOT activity at $37^{\circ} \mathrm{C}$. This residual activity is higher than we expected because our patients developed severe ketoacidotic crises, as SCOT-deficient patients with null mutations did. One possibility is that the findings in the fibroblasts may not be directly applicable to other organs. It is also possible that residual SCOT activity in vivo is somewhat different from that in vitro. Another possibility is 

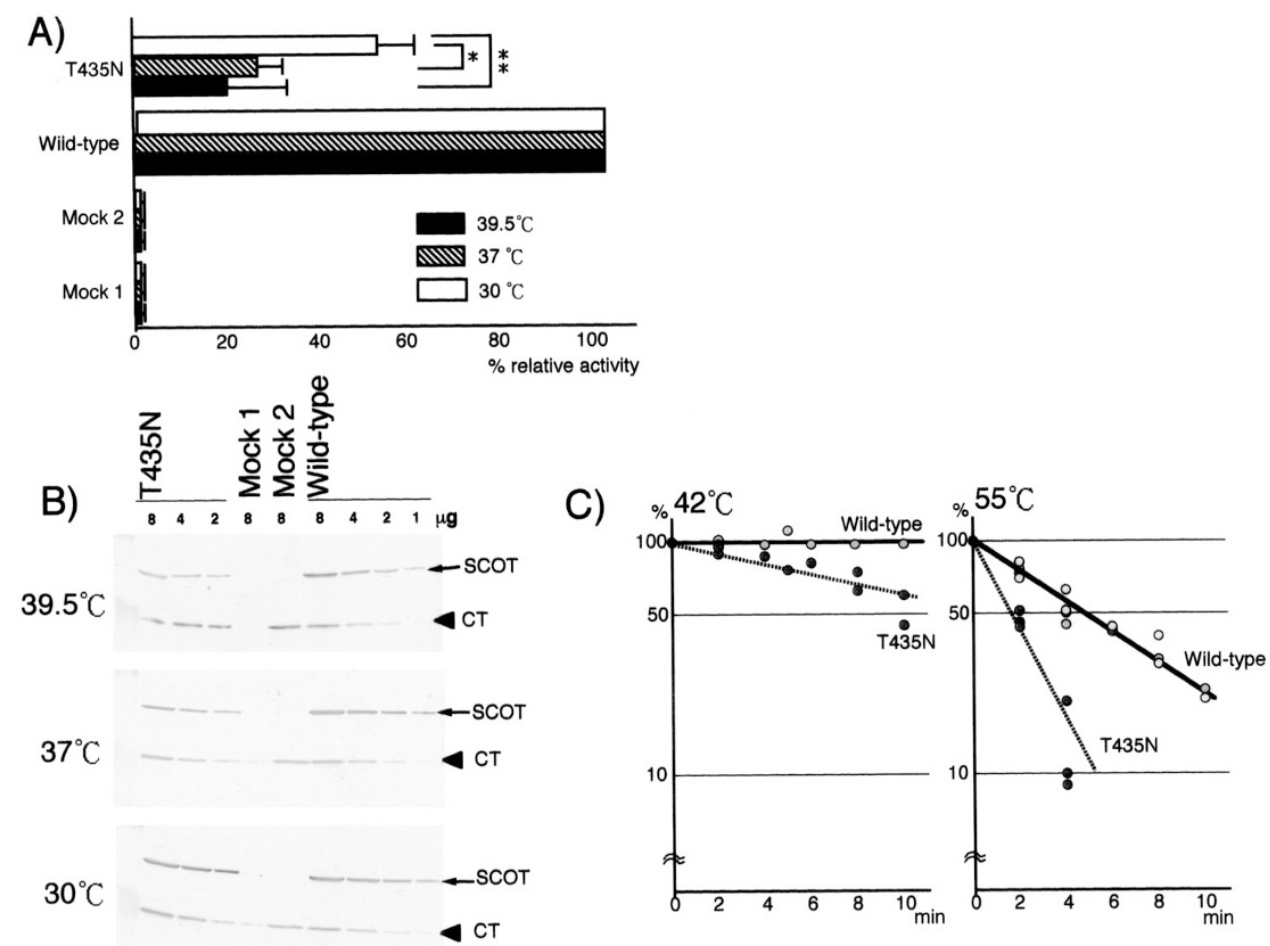

Figure 4. Transient expression results for wild-type and mutant SCOT cDNAs. Wild-type and mutant SCOT expression vectors $(4 \mu \mathrm{g})$ were transfected together with $1 \mu \mathrm{g}$ of the cytosolic acetoacetyl-CoA thiolase (CT)-expressing vector, pCAGGSct (20), to a SV40-transformed SCOT-deficient fibroblast cell line. After transfection, a 72 -h incubation was done at $30^{\circ} \mathrm{C}, 37^{\circ} \mathrm{C}$, or $39.5^{\circ} \mathrm{C}$. Mock $1,5 \mu \mathrm{g}$ of pCAGGS vector without insert. Mock 2 , transfection of $1 \mu \mathrm{g}$ of pCAGGSct and $4 \mu \mathrm{g}$ of pCAGGS vector without insert. (A) SCOT activities relative to those in pCAGGSscotWild-type transfection. Values shown are mean + SD of three experiments. Residual SCOT activity in pCAGGSscotT435N transfection at $30^{\circ} \mathrm{C}$ was significantly higher than those at $37^{\circ} \mathrm{C}$ and $39.5^{\circ} \mathrm{C}(t$ test; $* p=0.011$, ** $p$ value $=0.014) .(B)$ Immunoblots for SCOT and CT. Lysates from the indicated sources and amounts of protein were applied. The positions of the SCOT and CT polypeptides are indicated. $(C)$ Heat-stability test for enzyme activity. Protein concentration of the supernatant was adjusted to $0.5 \mathrm{mg} / \mathrm{mL}$ with extraction buffer, then incubated for up to $10 \mathrm{~min}$ at $42^{\circ} \mathrm{C}$ or $55^{\circ} \mathrm{C}$. The supernatant was kept on ice for at least 5 min and assayed for SCOT activity at $30^{\circ} \mathrm{C}$.

that febrile conditions reduce their SCOT activity since GS08 and GS09 developed ketoacidosis in febrile conditions. We investigated the thermostability of wild-type and mutant SCOT proteins in two ways. First, we performed transfection analysis at $30^{\circ} \mathrm{C}, 37^{\circ} \mathrm{C}$, and $39.5^{\circ} \mathrm{C}$. Transfection at lower temperatures gave a higher accumulation of SCOT protein and correspondingly higher SCOT activity $\left(20 \%, 25 \%\right.$, and $50 \%$ at $39.5^{\circ} \mathrm{C}, 37^{\circ} \mathrm{C}$, and $30^{\circ} \mathrm{C}$, respectively). Second, we examined heat instability for SCOT enzyme activity at $42^{\circ} \mathrm{C}$ and $55^{\circ} \mathrm{C}$. The $\mathrm{T} 435 \mathrm{~N}$ mutant exhibited heat instability for enzyme activity at both temperatures. This thermo-instability of the T435N mutant protein would make these patients more susceptible to ketoacidosis in febrile conditions that themselves are prone to cause physiologic ketosis even in normal children.

Although GS08, GS09, and GS09b have not had permanent ketosis, they still have characteristic laboratory findings that make one suspect SCOT deficiency. They developed severe ketoacidotic crises with a blood pH of 6.96 in GS08, 7.09 in GS09, and 7.00 in GS09b. Such a severe ketoacidosis is uncommon in ketosis associated with the normal physiologic response to fasting and other stresses. The fasting test of GS08 at $2 \mathrm{y}$ of age showed a rapid increase of total ketone bodies to a ketoacidotic level of $>6 \mathrm{mM}$ after $14-16 \mathrm{~h}$ and the ratio of FFA to TKB decreased to $<0.3$ after $14-16 \mathrm{~h}$ of fasting (Fig. $1)$. These findings are sufficient to raise suspicion of ketolytic defects (21), including SCOT deficiency. Carefully managed functional testing by ketolytic stress like fasting can be useful. As shown in Figure 2, overnight fasts (15 h) of GS02 at $9 \mathrm{y}$ of age and GS02s at $7 \mathrm{y}$ of age resulted in abnormally high levels of total ketone bodies and even $2 \mathrm{~h}$ after eating, their levels were much higher than normal $(<0.1 \mathrm{mM})$. In contrast, in GS09 at 4 y of age and GS09b at 8 y of age, overnight fasting resulted in almost normal levels of total ketone bodies, and postprandial levels of total ketone bodies decreased to some extent, but still higher than the normal range $(<0.1 \mathrm{mM})$. This overnight fast test followed by postprandial measurement of TKB (or 3-hydroxybutyrate) and of FFA is informative both for the diagnosis and management of patients who experience ketoacidotic episodes.

Persistent ketosis is a pathognomonic feature of SCOT deficiency, hence if present, it is an important clinical clue for suspecting SCOT deficiency. However, the absence of permanent ketosis does not exclude the diagnosis of SCOT deficiency with "mild" mutations. Because ketoacidotic crises in patients with "mild" mutations may be as severe as patients with null mutation in each allele and preventive treatment for SCOT deficiency is relatively simple and efficient, it is important to diagnose such patients. The severity of ketoacidosis during crises and the presence of postprandial ketosis may be signs of SCOT deficiency. 
Acknowledgments. The authors thank N. Sakaguchi for technical assistance.

\section{REFERENCES}

1. Mitchell GA, Fukao T 2001 Inborn errors of ketone body catabolism. In: Scriver CR, Beaudet AL, Sly WS, Valle D (eds) Metabolic and Molecular Bases of Inherited Disease, 8th Ed. McGraw-Hill, New York, pp 2327-2356

2. Tildon JT, Cornblath M 1972 Succinyl-CoA:3-ketoacid CoA-transferase deficiency. A cause for ketoacidosis in infancy. J Clin Invest 51:493-498

3. Spence MW, Murphy MG, Cook HW, Ripley BA, Embil JA 1973 Succinyl-CoA:3ketoacid CoA-transferase deficiency: a new phenotype. Pediatr Res 7:394

4. Saudubray JM, Specola N, Middleton B, Lombes A, Bonnefont JP, Jakobs C, Vassault A, Charpentier C, Day R 1987 Hyperketotic states due to inherited defects of ketolysis. Enzyme 38:80-90

5. Middleton B, Day R, Lombes A, Saudubray JM 1987 Infantile ketoacidosis associated with decreased activity of succinyl-CoA:3-ketoacid CoA-transferase. J Inherit Metab Dis 10:273-275

6. Perez-Cerda C, Merinero B, Sanz P, Jimenez A, Hernandez C, Garcia MJ, Ugarte M 1992 A new case of succinyl-CoA:acetoacetate transferase deficiency. J Inherit Metab Dis $15: 371-373$

7. Sakazaki H, Hirayama K, Murakami S, Yonezawa S, Shintaku H, Sawada Y, Fukao T, Watanabe H, Orii T, Isshiki G 1995 A new Japanese case of succinyl-CoA:3ketoacid CoA-transferase deficiency. J Inherit Metab Dis 18:323-325

8. Fukao T, Song XQ, Watanabe H, Hirayama K, Sakazaki H, Shintaku H, Imanaka M, Orii T, Kondo N 1996 Prenatal diagnosis of succinyl-coenzyme A:3-ketoacid coenzyme A transferase deficiency. Prenat Diagn 16:471-474

9. Pretorius CJ, Loy Song GG, Bonnici F, Harley EH 1996 Two siblings with episodic ketoacidosis and decreased activity of succinyl-CoA:3-ketoacid CoA-transferase in cultured fibroblasts. J Inherit Metab Dis 19:296-300

10. Niezen-Koning KE, Wanders RJ, Ruiter JP, Ijlst L, Visser G, Reitsma-Bierens WC Heymans HS, Reijngoud DJ, Smit GP 1997 Succinyl-CoA:acetoacetate transferase deficiency: identification of a new patient with a neonatal onset and review of the literature. Eur J Pediatr 156:870-873

11. Snyderman SE, Sansaricq C, Middleton B 1998 Succinyl-CoA:3-oxoacid CoA transferase deficiency. Pediatrics 101:709-711
12. Fukao T, Mitchell GA, Song XQ, Nakamura H, Kassovska-Bratinova S, Orii KE, Wraith JE, Besley G, Wanders RJ, Niezen-Koning KE, Berry GT, Palmieri M, Kondo N 2000 Succinyl-CoA:3-ketoacid CoA transferase (SCOT): cloning of the human SCOT gene, tertiary structural modeling of the human SCOT monomer, and characterization of three pathogenic mutations. Genomics 68:144-151

13. Berry GT, Fukao T, Mitchell GA, Mazur A, Ciafre M, Gibson J, Kondo N, Palmieri MJ 2001 Neonatal hypoglycemia in severe succinyl-CoA:3-ketoacid CoA transferase (SCOT) deficiency. J Inherit Metab Dis 24:587-595

14. Kassovska-Bratinova S, Fukao T, Song XQ, Duncan AM, Chen HS, Robert MF, Perez-Cerda C, Ugarte M, Chartrand C, Vobecky S, Kondo N, Mitchell GA 1996 Succinyl CoA:3-oxoacid CoA transferase (SCOT): human cDNA cloning, human chromosomal mapping to $5 \mathrm{p} 13$, and mutation detection in a SCOT-deficient patient. Am J Hum Genet 59:519-528

15. Song XQ, Fukao T, Mitchell GA, Kassovska-Bratinova S, Ugarte M, Wanders RJ, Hirayama K, Shintaku H, Churchill P, Watanabe H, Orii T, Kondo N 1997 SuccinylCoA:3-ketoacid coenzyme A transferase (SCOT): development of an antibody to human SCOT and diagnostic use in hereditary SCOT deficiency. Biochim Biophys Acta 1360:151-156

16. Song XQ, Fukao T, Watanabe H, Shintaku H, Hirayama K, Kassovska-Bratinova S, Kondo N, Mitchell GA 1998 Succinyl-CoA:3-ketoacid CoA transferase (SCOT) deficiency: two pathogenic mutations, V133E and C456F, in Japanese siblings. Hum Mutat 12:83-88

17. Fukao T, Song XQ, Yamaguchi S, Hashimoto T, Orii T, Kondo N 1996 Immunotitration analysis of cytosolic acetoacetyl-coenzyme A thiolase activity in human fibroblasts. Pediatr Res 39:1055-1058

18. Williamson DH, Bates MW, Page MA, Krebs HA 1971 Activities of enzymes involved in acetoacetate utilization in adult mammalian tissues. Biochem J 121:41-47

19. Niwa H, Yamamura K, Miyazaki J 1991 Efficient selection for high-expression transfectants with a novel eukaryotic vector. Gene 108:193-199

20. Song XQ, Fukao T, Yamaguchi S, Miyazawa S, Hashimoto T, Orii T 1994 Molecular cloning and nucleotide sequence of complementary DNA for human hepatic cytosolic acetoacetyl-coenzyme A thiolase. Biochem Biophys Res Commun 201:478-485

21. Bonnefont JP, Specola NB, Vassault A, Lombes A, Ogier H, de Klerk JBC, Munnich A, Coude M, Paturneau-Jouas M, Saudubray JM 1990 The fasting test in paediatrics: application to the diagnosis of pathological hypo- and hyperketotic states. Eur J Pediatr 150:80-85 